\title{
Ayta's Indigenous Healthcare Practices: A Descriptive-Qualitative Study
}

\author{
Yves Clark Fabrigas, RN, LPT, MAEd, MAN \\ Bataan Peninsula State University, Philippines \\ Jestoni D. Maniago, RN, RM, LPT, MAN, MAEd, \\ DNS, FRIN, FRIHC, FRIMW \\ Majmaah University, Kingdom of Saudi Arabia
}

Doi: 10.19044/esj.2018.v14n3p408 URL:http://dx.doi.org/10.19044/esj.2018.v14n3p408

\begin{abstract}
This descriptive qualitative study aimed to describe the healthcare practices of Aytas at Lakas Pamayanan, Philippines. The researchers who were culturally immersed to the community involved 100 Aytas of LAKAS Pamayanan who comprised of tribal leaders, tribal healers and tribal members. Ethical approval was secured from appropriate agencies and the participants provided their consent to conduct this research. Research techniques employed were interviews, non-participant observation and video documentation. For almost three years of cultural immersion and data gathering, the following insights were revealed: (1) Aytas still believed that sickness was caused by weather, 'kamana' and supernatural forces of nature. (2) The diversity of herbal medicines and its preparation have cultural importance to Aytas' different stages of life and different healing practices. (3) Aytas still used natural supplements such as bamboo blades for cutting umbilical cords and 'bigkis' for Ayta women who have just given birth. (4) There were not much of healthcare practices during puberty, adolescence and adulthood except for menstrual beliefs and circumcision because these part of their lives was concerned to their cultural views. (5) Aytas perceived that technology, media and modernization as well as the medical missions and outreach programs disconnect them from their cultural identity. (6) Aytas have shown some reception to public health programs such as hygiene. Aytas were able to preserve their cultural healthcare practices up to this time. It was recommended to develop a culturally-congruent nursing care model that will streamline evidence-based practice for indigenous groups in the Philippines.
\end{abstract}

Keywords: Nursing, traditional knowledge, health care, descriptivequalitative, Philippines 


\section{Introduction}

Philippines, like any other Asian country, has a very wealthy culture that even extends to the way they exercise healing and healthcare practices. Trinh- Shevrin (2009) stated that different Asian cultures apply various models in perceiving and interpreting symptoms and illness. These models influence their decisions to seek medical treatment and services. A key principle shared by many Asian cultures is a holistic view of health, with an emphasis on balance and harmony between the individual's mind, body, and environment.

According to Downey (2012) nursing scholars of healthcare practices are paving the way in articulating an indigenized approach to nursing indigenous populations. The concept of 'self-determination' and the utilization of traditional knowledge and medicines among indigenous peoples is not just 'nice to know' but a critical area of awareness and understanding that needs to be captured in educational curricula. A foundation of evidence is slowly being established towards the achievement of this objective with the development of theoretical information in the areas of cultural competency and cultural safety. We also need champions in our learning institutions that can break down the barriers towards developing and integrating such curricula and ensure that it is grounded in an accurate historical perspective consistent with the experience of indigenous populations.

Health is a cultural concept because culture frames and shapes how we perceive the world and our experiences. The religious and cultural beliefs of the Aytas result in many health care beliefs and practices which are significantly different from the dominant Filipino culture.

Only by understanding the cultural belief system of this minority sect can I, as a nurse practitioner effectively can help meet the health care needs of their community.

Aytas are not only seen as those people living in mountain parts of Zambales, they are not only those indigenous people who demonstrate the invisible thread that connect us from our ancestors and to what are us today and the future. They should not only be seen as people going down on lowlands to sell lowlanders' favorite orchids, creatively made hunting arrows, the gugu, kamote (sweet potato), pulot (honey) and even bonsai. At times, they are seen joining the celebrations on every Catholic feast (piyesta) wondering how on earth did they memorize all the town celebrations and fiesta without even having the calendar hanging on their walls.

These people are so fascinating, trying to preserve their culture and traditions while modernizations are slowly yanking them for every bit of changing scheme that might affect their way of life that was long been nourished by their descendants.

Aytas have unique form of survival. They are the indigenous people that never fail to mesmerize every professional, every historian and even the 
simplest resident. They find ways to thrive in every disastrous strike of nature and every changing hand of the Earth. They flourish in their ancient technique; they survive by their deep-rooted wisdom and they subsist by their prehistoric method.

Even United Nations Educational, Scientific and Cultural Organization has defined people like Aytas in a very enthralling manner. Indigenous people truly have their self-defined knowledge which according to UNESCO (2017) is a knowledge systems' which often referred to as traditional ecological knowledge or indigenous or local knowledge. They encompass the sophisticated arrays of information, understandings and interpretations that guide human societies around the globe in their innumerable interactions with the natural milieu: in agriculture and animal husbandry; hunting, fishing and gathering; struggles against disease and injury; naming and explanation of natural phenomena; and strategies to cope with fluctuating environments.

Furthermore, Prott and Bridgewater (2016) also stressed that this knowledge is passed from generation to generation, usually by word of mouth and cultural rituals, and has been the basis for agriculture, food preparation, health care, education, conservation and the wide range of other activities that sustain societies in many parts of the world.

Truly, Aytas do not necessarily claim to be the only people native to Zambales, but in many cases Aytas are indeed "aboriginal" or "native" to the lands they live in, being offspring of those peoples that inhabited a territory prior to colonization and prior to the present state of the government. They have their native ways on living, survival and even practices concerning healthcare which is the focal point of this study.

Throughout Zambales, Aytas have advocated for the right to retain their cultural beliefs and traditional medicine practices which rooted in spiritual and herbal medicine type of providing health care. This right on retaining their healing and healthcare practices is supported even by one of the most recognized body in the world - the United Nations.

In fact, in 2007, the more than 370 million people representing 5000 distinct groups throughout the world received global recognition with the adoption of the United Nations Declaration on the Rights of Indigenous Peoples (UNDRIP). UNDRIP Article 24 affirms the rights of indigenous peoples to their traditional medicines and health practices, and to all social and health services (Carrie et al, 2016).

Aytas healthcare practices are based on traditional knowledge. Moreover, traditional knowledge as defined by Assembly of First Nations in 2016 is the collective knowledge of traditions used by indigenous groups to sustain and adapt themselves to their environment over time. Traditional knowledge is unique to indigenous communities and is rooted in the rich 
culture of its peoples. The knowledge may be passed down in many ways, including: storytelling, ceremonies, dances, traditions, arts and crafts, ideologies, hunting/trapping, food gathering, spirituality, teachings, innovations and medicines.

A lot of people supports natives' old way of healing practices just like on what Warne (2015) points out, that it is somewhat ironic that modern physicians say they provide healthcare when they really treat diseases unlike to traditional medicine.

Every treatment has a cultural component. The present medical practitioners teach the importance of evidence-based medicine, but will the advancement of Science just dispatched and will dismiss all the holistic and traditional way of healing and practices of our natives because of the undeniably effect of the modern medicine?

Erasing cultural traditions in all areas even in healing or healthcare may somewhat efface prints of the past that connects us to our origin. Besides, traditional or indigenous ways of healing and healthcare practices are valuable because of a lot of things which is why this study was made.

The following are the main reasons of accomplishing this study: (1) Aytas healthcare practices contains innumerable folk remedies based on plants, many of which have formed the basis for pharmaceutical treatments that are used routinely in modern medicine; (2) much of Aytas traditional healing centers around group ceremonies, including prayers, the sharing of a meal, the use of traditional medicines and practices where healing also involves feeling part of a shared culture, of being outdoors and in connection with the land and with nature; (3) the healing relationship is based on a series of virtues: respect, humility, compassion, honesty, truth, sharing, hospitality and divine love and; (4) traditional approaches to healing of Aytas are holistic and consider mind, body and spirit.

Health care providers are more likely to have positive interactions with patients and provide better care if they understand what distinguishes their patients' cultural values, beliefs and practices from their own.

It is important to know the cultural traditions of ethnic group to better address the healthcare needs of individuals. Lima et al (2016) said that with regard to health and diversity, it is impossible to think about humanity without beliefs and religions, as it is to consider medicine and therapies from diverse societies without a fetishist and magical-religious background. Every therapeutic system is an indissoluble part of society's cultural repertoire, as an integral part of culture, being influenced by it and vice-versa. This is because homemade preventive and therapeutic measures aim to seek or maintain a level of well-being close to that regarded as ideal. These practices are, in general, performed in the family context and almost always passed on from generation to generation. 


\section{Method}

\section{Research Approach}

The focus of our research was on exploring and describing the indigenous healthcare practices of Aytas at Lakas Pamayanan, Philippines. For this study, we chose to apply a qualitative descriptive approach as outlined by Sandelowski (2000). There is no clearly defined approach to qualitative descriptive studies (Milne \& Oberle, 2005). Qualitative descriptive studies tend to be more naturalistic in that they employ neither the philosophical underpinnings nor the interpretive requirement to search for higher meaning associated with phenomenology; nor do they require the advancement of findings to higher theoretical concepts or abstractions consistent with grounded theory approaches. A qualitative descriptive study is suitable when detailed descriptions of phenomena and a focus on the presentation of participants' dialogue with the researchers are desired (Sandelowski,2000). Clearly, the qualitative descriptive method is one method of choice for a research endeavour that seeks to present the voice of the particular population under study. Using this approach, the researchers remain closer to the words and meanings offered by informants and is able to offer a comprehensive summary of a phenomenon in everyday terms, or at least with minimal abstraction, organized in the way that best fits both the data and the audience for whom it is written (Sandelowski, 2000).

\section{- Participants}

There were 100 participants purposively selected according to inclusion-exclusion criteria. The participants were tribal leaders, tribal healers, hilot and Aytas who have knowledge on Aytas' healthcare practices in LAKAS Pamayanan, in Bihawo-Villar, Botolan, Zambales, Philippines.

\section{Research Instruments}

The instruments that were used in this study are the non-participant observation, semi-structured interview and documentary.

Interview. The interview is the main instrument in this study. The interview guide used is divided into four parts which were: The semistructured interview is divided into three parts: (1) healthcare practices related questions (2) healthcare tools related questions (3) factors affecting Aytas' healthcare practices.

Interview guide questions were translated into the Aytas' native dialect which is the Sambal Botolan by the tribal chieftain Fe Epang Domulot-Balbin. Dialect translation was done so that Aytas could answer each query in a more at ease manner, that way, they comfortably share their ideas and experiences that pertains to the questions being asked. 
Before an interview took place, we informed the Aytas about the study details and gave assurance about ethical principles, such as anonymity and confidentiality. This gave the participants some idea of what to expect from the interview which increased the likelihood of honesty. Establishing rapport with participants prior to the interview was also done, as this had a positive effect on the subsequent development of the interview.

In conducting the actual interview, we attentively listened to what is being said, so that participants were able to recount their experiences as fully as possible, without unnecessary interruptions.

At the end of the interview, we expressed gratitude and asked the participants if there was anything they would like to add. This then gave the participants an opportunity to deal with issues that they have thought about, or believed were important but have not been dealt with interviewer process. This then led to the discovery of new, unexpected information.

\section{Non-Participant Observation}

It was validated through the observation of the Aytas' nonverbal expression, feelings, healthcare interactions in the community and observations on how they react to certain questions in the interview process.

\section{Documentary}

It was done through photographed images, field diary, publications and video recordings. Documentary validation will be done through document appraising. Appraising documents is a process of validating documentary which typically includes four criteria: authenticity, credibility, representativeness, and meaning (Scott, 2007).

\section{Data Gathering Procedure}

Stage 1: Permission to conduct the study from National Commission of Indigenous People was sought, for the ethical consideration that needs to be addressed in performing the said study. Since, a primary consideration in any research study is to conduct the research in an ethical manner, letting the community know that one's purpose for observing is to document their activities.

Stage 2: Permission to conduct the study was asked to the community leader of LAKAS Pamayanan. Ethical consideration was also practiced in this study such as keeping the confidentiality of the participants, key informants, and the elders.

During the meeting of LAKAS Pamayanan community members for the first time, informing the purpose of the study will be done, sharing sufficient information with them about the research topic that their questions about the study. 
Another ethical responsibility is to preserve the anonymity of the participants in the final write-up and in field notes to prevent their identification, where individual identities must be described in ways that community members were not be able to identify the participants.

Stage 3: Scrutinizing of Aytas' knowledge and observation of their healthcare practices based on researcher's three (3) years of living in the said community were organized as soon as permission to conduct the study was obtained.

Stage 4: A preliminary observation and interview were conducted.

Stage 5: Noting significant details on the health care beliefs and practices of the Aytas, the researcher assessed the gathered data based on the previous stages of data gathering and noted significant details related to the topic.

Stage 6: Conducting interviews focusing on the healthcare beliefs and practices. After determining the important points to be considered, interviews were done.

Stage 7: Collecting data from other sources. After the observations and interviews made by the researchers, documents that reflected the health care of Aytas in the LAKAS Pamayanan were examined. At the same time, gathering information through documents related to healthcare among Aytas was ensured.

\section{Results and Discussion}

\section{The Healthcare Practices of Aytas towards Disease and Healing}

The Aytas of LAKAS Pamayanan believe that diseases are brought by weather. According to some of the participants, when an Ayta has fever, flu or runny-nose, it is believed to be caused by parching in the sun or rain.

They also believed that their sickness is caused by spirits or souls of the departed.

Since Aytas believe in the supernatural forces of nature, when one gets sick they also perceive that this might be because of accidentally or intentionally hurting nature's spirit be it the lake, the trees, birds or flowers.

One of the initial responses that Aytas do when one is confronted by sickness is to offer food or other stuff to the spirits or to their ancestors.

"Hay nanay ko ay ampag-alay nin tabako, alak buy posporo nu main hakon hakit. Anhumampat hiko itaman. Ampako ko kasi ha lugar ya an ibawal ya taw-tua.." (My mother used to offer cigarettes, cheap liquor and a match whenever I get sick. After 2 days, I got healthy again. I experienced getting sick because I used to go to forbidden places,) - Participant A.

This might be devoid by scientific rigor but this is how the indigenous group of people in LAKAS Pamayanan addresses their healing and sickness 
practices. This in particular is supported by the declaration of Torres (2012) that when one of the Ayta falls ill a culturally normal response is to offer food to the ancestor to seek forgiveness.

Aytas' belief in spirit is also stressed by Torres (2012). Torres that Ayta also believe that a person gets sick because of not respecting other creations and that before the healers can perform healing; they need to consult the spirit. This is the only time they can diagnose the cause of the illness.

"Main anhalitain la ya Baylan ya ansaniban ni Apo Namalyari ya mangituro nu hino ya ma-in manambal nin komunidad. $\mathrm{Nu}$ agmo inggalang ya aw-elemento, pamasakiten la ka, makatambal ya Baylan maliban ha hakit ya kanser o katuwa ya mahakit." (There is what you call Balyan, who is being possessed by Apo Namalyari (Supreme Creator) and will identify who will become the healers (manganito) of the community. When you disrespect the elements of nature and get sick, the Balyan can also cure you except diseases like cancer, or anything serious.) - Participant B

There are Balyan in Lakas according to the father of the chieftain. There children can also be tasked as Balyan. Being humans, they can also get sick and get hospitalized. They are more powerful than manganito (healer) because they are said to be possessed by Apo Namalyari. However, the chieftain's father did not disclose to me the names of these people as part of their culture.

\section{The Healthcare Practices of Aytas during Pregnancy and Child Birth}

The Ayta woman gave birth as early as 16 years old. As narrated by Participant C:

"Hin hiko ay nabuktot agla ko ambyan nin kalako ya itsura ya paw-prutas kasi ahe mag-in normal ya kulaw ha buktot ko. Agla ko ampayagan manakel nin nu anya anya ta mairap nin manganak." (During my pregnancy stage I was not given any unusual looking fruit, vegetable or food because it may cause some abnormalities of the fetus on my womb. I was not allowed to tie anything- like a knot since it would make my child delivery so difficult. The delivery of my child was done by a hilot. The hilot massaged my tummy on my 5th month believing that it would expedite my delivery.)

By the time of the delivery of the child Ayta also performs some practices that are distinctive. Participant D, age unknown, also recounts these practices.

"Nin nanganak hiko, napanemteman ko ya main lan ginamit kungko ya matarem ya kapirason kawayan ya pinamputo la ha 
pohel. Dahil mairap ya panganak ko, nakaira akon bungat. $\mathrm{Nu}$ hika ay mahukaw ya babayi, mangalimokor kan manganak. Pagkayari Maputo ya pohel, ampuolan imen maitago nin nanay. Agnawen an ihipen ya kayi ay makapoy ya babayi. Ampagtraho kayi pagkayari manganak." (When I gave birth I remember seeing the hilot cut the umbilical cord of my child by a blade which was made by some of our tribal people, but for some of my relatives they told me that they remembered that it was a sharpened bamboo blade that cuts the umbilical cord of their child. Because I am very weak and struggled giving birth, I did my child delivery in a lying down position, but if a woman is strong, in our culture it was done in an either sitting or kneeling position. After the umbilical cord was cut it was then burned into ashes and the ashes were then kept by the mother. We do not really treat ourselves to be that vulnerable after giving birth, in fact right after the delivery of the child we then can go back to our normal chores and duties at home. Our husbands would offer sweet potatoes or other root crops so that we become stronger while doing hard labor.)

Another statement from other participants stated that they are asked to wear 'bigkis' or a cloth tied on their abdomen for a month, so that the blood would not go up to their hearts.

Based on the testimonies above, Ayta women believe that eating food that look unusual may copy the form of life that is in their womb, like if they eat twin bananas they would likely to have twins.

These demonstrations are strengthened by Randall (2008) as he stated that Ayta women give birth easily and are able to resume work a few hours after delivery and to prevent a difficult childbirth, she should refrain from stepping on cordage or tying knots.

In 2015, three of Grade 10 completers became pregnant at the age of 16, 15 and 17. Though we were not able to witness the actual delivery, we were shocked to see one of them carrying two pails of water a day after her delivery. It was alarming for me because of possible bleeding and other complications can happen to her.

\section{The Healthcare Practices of Aytas during Puberty, Adolescence and Adulthood}

Like other tribes, the Ayta have some health care beliefs and practices during puberty, adolescence and adulthood as follows:

For female Aytas who have reached their puberty stage, during their first menstrual period they are not allowed to take a bath on the first day of their cycle since that would cause insanity as to them. This phase is kept from 
the elders because it is a taboo. They are not allowed to pass behind their parents for they will perish.

\section{Participant D recounted}

"Nin una kon nagkarigla, anha-aren lako nu mako ko ha bukot la. Antampalen la ko ta baka mati ko. Agla amparugaran ya malyo ko." (When I had my first menstruation, my mother would scold me when I stay or pass behind them. They would slap me because I might die. I was not allowed to take a bath even if I want to.)

For boys, they enter the phase of manhood through the ritual of circumcision called bugit. Young males aged 11 to 16 are circumcised, an indication that a boy's role is changing and he may soon take a bride soon. Herbal plants like guava leaves are boiled to clean the wound.

Like most of the lowlanders, circumcision is a big deal. They can become targets to jokes of being 'supot' or uncircumcised. Like my student who always had teary eyes; they believe that it was an effect of having a father who did not undergo the ritual of circumcision. This is a passage of manhood where one should undergo circumcision to overcome pain and be a part of a macho culture.

Not much of the practices of Aytas during this part of their lives concerns health care practices since this stage encompasses their cultural views on life.

Cultural performance with limited healthcare practices as mentioned above is also stressed by Grey (2016) when she verified in her study that this stage is not so much related to health care but more on cultural.

\section{The Healthcare Practices of Aytas during Old Age and Death}

They believe that they must not sweep the floor or take a bath as they mourn because it may cause illness or even death to another member of the family.

\section{Particpant E, 56, narrated}

"Ankaihipan ko nin anak ko ya nu main mati kunnawen, ahe la ang igwa ya nati ha kabaong ta pagpairyan nin ahe angkakit ya kabaong. Piro pagkalampas nin taon, ampagdonasyon ya gobyirno nin kabaong kaya antanggapen nawen. $\mathrm{Nu}$ antumuntawo kayi, agnawen labay ya magpatambal ha ospital. Ampintu-o kayi ya an-alalayan kayi nin aw-ispiritu buy ni Apo Namalyari."(I remembered when I was a child and we lost a love one, we usually do not put them on a coffin for we believe that coffin will be used by the bad spirits as their homes. But as 
the years passed we learned to adapt on the changing live style of our tribes, we then learn to use coffins for sometimes government officials would donate a beautifully engraved coffin. On our old age we do not really rely on hospitalization process when we are at our weakest stage of life. This is because we are intact to our belief that we will be guided by the spirits and Apo Namalyari in this part of our lives.)

Kalarat, 22, not her real name, who happened to become my friend, narrated to me that in Baytan (eastern part of Botolan, Zambales) when a love one dies, the relatives put leaves of langka (jackfruit) on the belly of the dead person to preserve it for days. This practice is expressive of ethnic and cultural identity and are strictly enforced by the community folks. That is why the natives grasp their way of healing so to preserve life even if they are in their far abode and hospitals are hours away.

Inadequate health conducts during this stage is revealed by the Aytas and because of their integral conviction on spirits to heal them they avoid any hospitalization that then leads to great percentage of adult mortality is therefore observed.

\section{Particpant F, 78, said}

"Ahe kayi ampako ha ospital ta marayo. Angkareng-ey kayi mako ha daw doctor ta main et an-ipapawa la kayi itaman. Angka imatonan nawen kaya ampagbira kayi ha datin kaugalian nawen. (We have no access to hospitalization because of the distance. Most of the time, we are shy to consult a doctor because people would still discriminate us. We can feel that... that is why we resort to our old ways of healing. We eat what are only available or what we can afford.)

The above declaration is also supported by a study done by Ocampo (2014) in which he stated that the short life span of the Negritos. The short life span is may be attributed to high adult mortality due to poor health habits, access to hospitalization and reliance to their belief in the spirits to cure their illness.

\section{The Healthcare Tools of Aytas}

Aytas have a rich knowledge on herbal medicines, below are the list of herbal medicine that they use in different types of sickness.

These herbal medicines are prepared in different ways like:

1. Macerations. This method of preparation is certainly the easiest. The fresh or dried plant material is simply covered in cool water and soaked overnight. The herb is strained out and the liquid is taken. Normally this is 
used for very tender plants and/or fresh plants, or those with delicate chemicals that might be harmed by heating.

2. Infusions are typically used for delicate herbs, leaves and fresh tender plants. Preparing an infusion is much like making a cup of tea. Water is brought just to a boil and then poured over an herb (or combination of herbs), it is covered and allowed to sit/steep for 10-15 minutes or so. It can be prepared in the drinking cup (by just pouring the heated water over the herb in the cup) or by dropping the herb into the pot which the water was heated in.

3. Decoctions are usually the method of choice when working with tougher and more fibrous plants, barks and roots (and which have water soluble chemicals). Instead of just steeping it in hot water, the plant material is boiled for a longer period of time to soften the harder woody material and release its active constituents.

4. Strong Decoctions. Depending on the type of plant material used, strong decoctions are prepared in two general ways. The first involves boiling the mixture longer. This is usually indicated when working with larger woody pieces of bark. Longer boiling time, up to 2 hours or more, is sometimes necessary to break down, soften, and extract the larger pieces. Alternatively, when smaller woody pieces are used yet a stronger remedy is wanted, the decoction is prepared as above (boiling 20 minutes).

5. Baths and Bathing Remedies. Baths and Bathing Remedies. The leaves of herbs are chopped and added directly on the water that will be used in bathing; or the leaves, bark or roots of plants are decocted and then poured on the water-bath

6. Poultices and Compresses. Many herbal remedies are applied directly to the skin as poultices - usually on rashes and wounds and as topical painrelieving remedies. Sometimes just enough hot water is poured over dried or fresh plant material to soften them. Then the wet herbs are placed directly on the skin or between two pieces of cloth and laid on the skin.

\section{Healing Rituals and Materials as Healthcare Tools of Aytas}

Particpant G, 15, daughter of one of the healers said:

"Ang kaimatonan ko ya nanay ko ya ampakiilgo ya ha aw ispiritu o anito ta magpahampat nin main haw hakit." (Having a mang-aanito mother, I observed how she talked to the spirits or anito as a way of interacting to them so to help the sick be healed and cured.)

One of the rituals is the 'Anituan' where the 'mang-aanito' talks to the spirit that has something to do with the sick person. This is a type of healing mortal to the spirits. 'Pang-aanito' is really part of the Aytas healing rituals, which is also verified by Balila et al. (2014) when they stressed that the ritual establishes close communication between the mortal and the 
supernatural world, so that misunderstandings between mortals and spirits may be resolved.

As narrated by Particpant $\mathrm{H}$, a tribal leader and healer, in his interview:

"Bayo ko magin mananambal,nataynepan ko ya kinayat hiko nin utan tatloy bisis at main napakit kungko ya naghalita ya hiko ay manambal ya gamiten ko kano ay laway buy bawbulong tanaman. Main hakon napagkalamo ha Mindanao ya main hakit. Tatloy bwan angkabaya ya nawini na, mapara mapakil, matag-ay ya hakit ulo buy ahe makaekan. Nilawayan ko ya at hinumampat ya. Byan nako dayi nin limay libo piro agko tinanggap. Hay hakit na ay nakwa na ha ispiritu." (Before I became a healer, I dreamt that I was bitten by a snake 3 times and an old man appeared to me that I will become a healer using different ways like herbal medicines and saliva. I remember when I was in Mindanao attending a convention, there was this participant who would not get healed from a mysterious sickness. For 3 months, his body is swollen, easily gets tired, with high fever, and cannot eat well. Using my saliva, he got well after some time. He tried to give me 5,000 pesos but I declined. His disease was inflicted by a kamana or soul of the dead.)

We could attest to the healing touch of Participant $\mathrm{H}$ who became a father figure to me the first time us stepped on the soil of LAKAS. According to Yves, "Even if I will not tell him how sick I am, he would automatically massage my back with a sort of whisper or chant. Although I do not agree with him using his saliva to me for I find it unhygienic, still, I respect him". Some of them recite chant or prayers while smoking some woods or plants before going for a hunt so that their Gods will protect them from sickness cause by weather and any other element of nature. One of the chants that they utter is:

"Apo ko dau-pen moyu po ya uhok, idayo muyo po kayi ha uran, ma-ingalo kayik ta mabaha kayi”. (Apo, smell the smoke, do not expose us to the rain, have mercy on us, because we might get wet.)

Chants are very important in Aytas way to avoid sickness as they believe that through this they would not be delivered to any ailment brought by weather. Caronongan (2005) backed up this declaration, as he indicated that the animist background of the Ayta also attributed a supernatural identity and powers to Mt. Pinatubo itself; the rain would stop and the weather cleared because of offerings and prayers. 


\section{Factors affecting the Healthcare Practices of Aytas Technology, Media and Modernization}

Technology, media and modernization had affected the way Aytas perform their healthcare practices, some of the rparticipants stated the following passages concerning these matters.

"Nayari hana ya alloy aw-Ayta ay ayin tanda. Ampakabiliw kayi hana nin tilibisyon buy main hanan gamit ya kanayon ha gawgamit nin taw-tua. Tanda nawen hana ya anhaliwen nawen ya taw tambal ha botika piro agnawen labay inumen ya tambal." (Gone are the days where Aytas are labelled as illiterate or lack from technical knowledge. Some of us are now being exposed if not equipped to gadgets like television that add some awareness to us on how we do things, differently from what was being taught to us by our fore fathers. With the aid of Technology, Media and Modernization we are being familiarized with the different medications that are made available over the counter, though we are not really using it most of the time, at least we know that there are medicines like some sort.) - Participant I

"Kaya ha cilpon nawen buy ha maestro nawen, ampakakwa kayin tambay ha ospital."

(With the use of cellular phones if not by us, or by some of the teacher that are part of our community mainly because they are being assigned to teach in our area, we get hospital help easier through this tool.) - Participant $\mathrm{M}$

"Maski na main maw moderno ya tiknolohiya, agnawen labay ta angkabura o angkahira ya kultura nawen. Main hikon pisbok buy ngkabaha ko ya aw artikulo du. Agko itaman pintu-wen." (Though modernization and technology gives positive outcomes on awareness even in healthcare issues I decline to this process because for the introduction of such things our social and cultural identity is slowly being erased. I have a Facebook account and I can read articles about contemporary healing methods. Some may look incredible though.) Participant A1

Gina, not her real name, once told us after class that she does not want to use the 'pasador' anymore because sanitary napkins can easily be bought in stores. She also refuses to use boiled guava leaves for her scabies because she thinks that antibiotic pills are easier to use and more effective. Since she has a Facebook account, she reads and shares what amazes her. Instead of the usual 'gugu' on her hair, she idolizes actresses with long straight hair and invests on commercial shampoos. 
The above stated information is supported by what Grey found out on her study. According to her due to the effects of modernization and information taken from the sources such as media and technology, Aytas have lost some of their tribal practices.

\section{Medical Missions and Outreach Programs}

Medical mission and outreach programs also affect the healthcare practices of Aytas in different ways. Most of the participants stated,

"Main ampwako ya medical missions di buy outreach programs ya angkaibat ya kanayon ya relihiyon buy grupo nin paw pulitiko. An ipahok la ya paniniwala la kaya angka ali kayi hana ha sarilin raw ritwal buy pamaraan nin paghampat." (Medical missions and outreach programs are usually done by different group of people with different religious and political affiliations, because of this some of us are being introduced to other religions which alter what we believe, making us somewhat detached to our rituals and healing practices.)

Other participants said,

"Agko tanda nu mahampat ya taw tambal ibat ha baw botika ta angkaliwawan nawen hana ya luma ya pamaraan." (We are being introduced to the mainstream medications that are brought by the outside community which in truth I do not know know if this is good or bad for we then forget our natural way of healing practices.)

Some participants said,

"Bana ha outreachprograms ya nangigwa nin aw impormasyon kun nawen ha makabayon taw tambal, mas mapara ya maihanda kisa mamabho nin bulong o mangwa ha bakil bana ya angkahaliw hana ha botika." (Because of the outreach programs that brought us knowledge on medicine aside from herbal one, I realize that it is sometimes easier to acquire those medicines and easy to prepare we do not need to boil them or gather them from the forest because it is readily available even in the nearest store in towns.)."

Yves reflected, "As a teacher who became concern with the health status of the Aytas, I have to initiate getting help from private individuals and organizations to do medical missions and outreach programs specifically for the students. For the year 2017, I have generated an amount worth 2 million pesos on goods and services rendered. This system of delivery of services to the people is quite tiring but fulfilling. However, this is the hardest part for me to do because some organizations help in favor of getting something particularly religious purposes and 
commercialism which may be derogatory in nature. Since majority of the Aytas are illiterate, they cannot do their part of avoiding being taken for granted."

\section{Government Health Programs}

Government health programs are undeniably a factor that affects the healthcare practices of the Aytas in LAKAS Pamayanan.

Because of the commissions and departments of government that extend helps to the tribal communities in the Philippines like the National Commission of Indigenous People and other government agencies that presents help and programs to the Aytas of LAKAS Pamayanan their healthcare practices are being shaken to some extent. Just like what other participants declared:

Participant N: "Maganda ya anggaw-en nin gobyirno ha pangituro kunnawen bana ha kaayusan nin nawini piro labay nawen dayi ay paw proyikto ya makatulong kunnawen ya pangmabuyotan. Nu main kabibiyay, mahaliw nawen ya gaw gamit ta emen mag-in makhaw. Tanda nawen ya maganda ya habon buy alcohol piro nu ayin panaliw, ayin et bungat labay tutulen. Angkakit muyo ya mairap kayi." (Awareness to hygienic habits provided by the government is good yet what we need is the sustainability project that could make us afford all the needed supplies to remain healthy. Yes, we might know that alcohol and soaps are good ways to prevent diseases yet without the means to buy it, the knowledge would be useless. Because as you see we are poor.)

Other participants said,

"Malhay ya tambay nin pawprograma nin gobyerno. Malkalako kayi hana ha aw ospital ta libri itaman hana, agkayi mati nin anak et."

(The government has provided health programs that benefited all of us. All of us now know that we can go the hospitals and get medical help with nothing to pay, that way we may not die young and lessen our high rate of mortality.)

Some expressed,

"Bana ha paw programa nin goyirno ha preparasyon ha kaw kalamidad, tanda nawen ha angga gaw-en nawen." (Because of the programs that are being done by the government like preparation in times of natural disaster we would be able to know what to do in case of emergencies.)

Others stated, 
"Luwa ya programa nin gobyerno ay bana ha pagkontrol nin pagbuktot buy ha bakuna. Agnawen labay ta labay nawen ya malake ya anak. Kapalimo ya pagbakuna." (Some of the programs being offered by the government are birth control and immunization. I must admit that most of us are resistant to this programs, because we love having lots of children, as to immunization we feared this tool.)

We must accept the fact that help from the government is scarce. Pantawid Pamilyang Pilipino Program, also known as 4Ps, did not meet its expectation of helping the poorest of the Aytas. This conditional cash transfer program of the government was not able to eradicate extreme poverty among Aytas of Lakas Pamayanan probably due to some biases. There are no specific healthcare programs for these marginalized people of our society, though, it can be said that some programs like vaccination/immunization are given at times as needed. It is then true that the above factors have affected the way the Aytas practiced and perceived their native healthcare practices. This is supported by the study made by Gaillard (2007) which stated that Aytas from the upper slopes of the volcano, who discovered the way of life of the lowlanders during their stay in the evacuation centers, were the most prone to cultural change given by modernization, technology, media and medical help from different sectors that changes their way of life and practices.

\section{Conclusion}

An understanding of the health-cultural belief system of the Aytas in LAKAS Pamayanan is essential if nurse practitioners are to meet the health care needs of Ayta patients. Accounts provided by this study are provided as a means for nurses to understand the context in which many Aytas live today, which can adversely impact health status and healthcare acceptance that the nursing field might or should give them.

A non-judgmental, open attitude is required on the part of healthcare professionals to encourage Ayta families to attend clinics where health monitoring can be maintained and health education provided.

As nurse-teachers who witnessed the traditional practices and knowledge that provide a basis for positive self-image and healthy identity, it is significant that nurse practitioners should exercise holistic approach which is pivotal for Indigenous societies to regain their positive identity.

At the personal level, this means each member enjoys health and wellness in body, mind, heart, and spirit. Within the family context, this means mutual sustenance of each other. From a community viewpoint it means headship committed to whole health, empowerment, compassion to interrelatedness of past, present, and future possibilities, and connected 
between cultures. The interactions between cerebral, emotional, and spiritual stress and physical health are germane and important to Indigenous health. Understanding the fact that healthcare practitioners and nurses like Aytas of LAKAS Pamayanan do carry their cultural beliefs on them, thus this study might help to understand to respect each cultural view no matter how difficult it is and no matter how different it is from the other. Nurses should learn the proper way of explaining the modern healthcare practices without offending Aytas on what they believe in, because upsetting them is a way of disrespecting their culture that defines their identity.

- Recommendations

- It was recommended to develop a culturally-congruent nursing care model that will streamline evidence-based practice for indigenous groups in the Philippines, particularly Aytas of Lakas Pamayanan. It was highly encouraged to conduct similar research on indigenous health to further understand the traditional knowledge on healthcare practices.

\section{References:}

1. Carrie, H., Mackey, T. K., \& Laird, S. N. (2015). Integrating traditional indigenous medicine and western biomedicine into health systems: a review of Nicaraguan health policies and miskitu health services. International journal for equity in health, 14(1), 129.

2. Gaillard, J. (2006). Traditional societies in the face of natural hazards: the $1991 \mathrm{Mt}$. Pinatubo eruption and the Aetas of the Philippines. International Journal of Mass Emergencies and Disasters, 24(1), 5.

3. Grey, E. J. Cultural Beliefs and Practices of Ethnic Filipinos: An Ethnographic Study. Social Sciences, 3(03), 2016.

4. Ocampo, R., \& Ocampo, R. E. M. A. (2014). The economic life of the negritos of Luna, Apayao. Asia Pacific Journal of Multidisciplinary Research, 2(1). Randall, John. (2008). Negritos of the Philippines.

5. Sandelowski, M. (2000). Focus on research methods-whatever happened to qualitative description?. Research in nursing and health, 23(4), 334-340.

6. Torres, R. A. (2012). Aeta women Indigenous healers in the Philippines: Lessons and implications (Doctoral dissertation, University of Toronto (Canada)).

7. Trinh-Shevrin, C., Islam, N. S., \& Rey, M. J. (Eds.). (2009). Asian American communities and health: context, research, policy, and action (Vol. 22). John Wiley \& Sons. 
8. Vaismoradi, M., Turunen, H., \& Bondas, T. (2013). Content analysis and thematic analysis: Implications for conducting a qualitative descriptive study. Nursing \& health sciences, 15(3), 398-405.

9. UNESCO. (2015). Social practices, rituals and festive events. retrieved from URL http://www.unesco.org/culture/ich/en/social-practicesrituals-and-00055 